Journal of Sustainable Agricultural Sciences
http:/jsas.journals.ekb.eg/

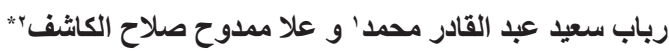

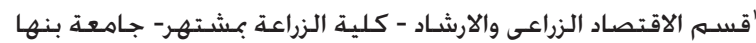

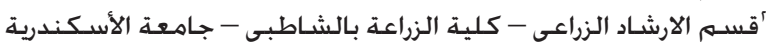

إستهدف هذا البحث التعرف علي معارف وتنفيذ الزراع والمتعلق بعدد من التوصيات الإرشادية الفنية الخاصة

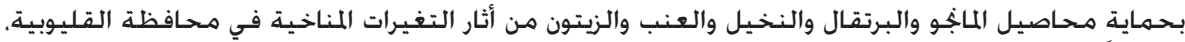

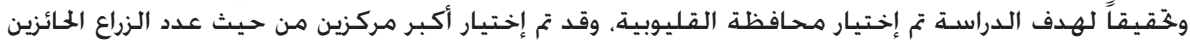

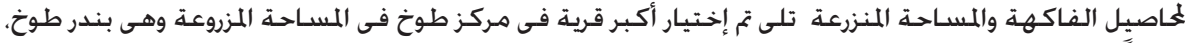

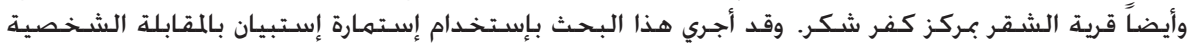

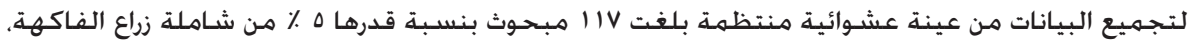

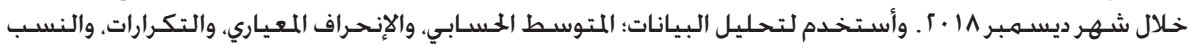

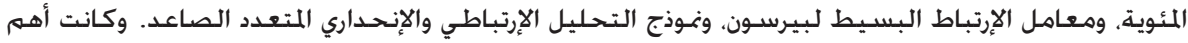

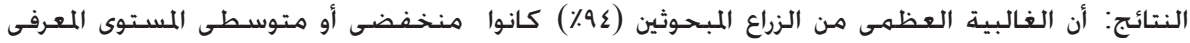

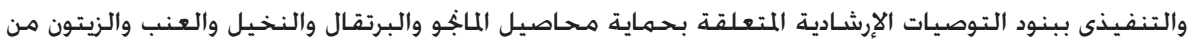

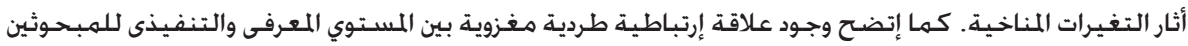

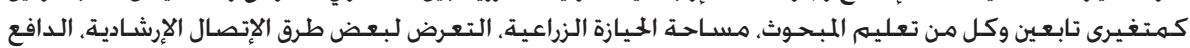

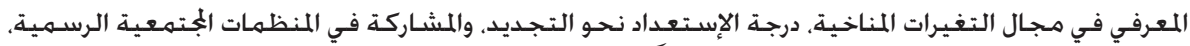

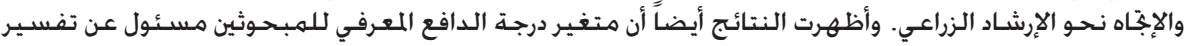

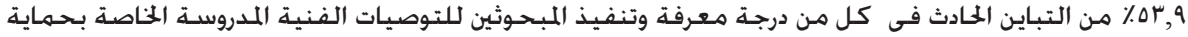
بعض محاصيلههم من أثار التغيرات المناخية.

كلمات دليلية: التغيرات المناخية، معارف، تنفيذ، محاصيل الفاكهة، التوصيات الإرشادية الفنية، الزراع، منهاع. محافظة القليوبية.

للغاية للمناخ والطقس؛ هذه هي بعض أكبر عوامل الخطر في

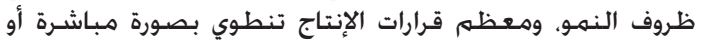

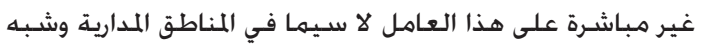

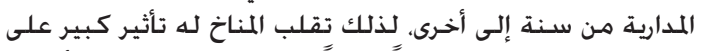

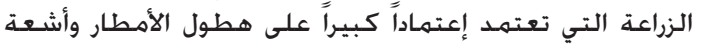

الشـمس ودرجـة الحرارة (Chouhan, 2018).

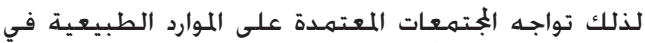

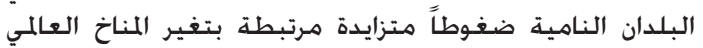

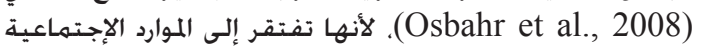
والتكنولوجية والمالية اللازمة للتكيف مع تلغير المناخ والتخفيف المارديف

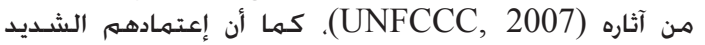

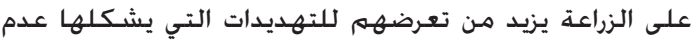

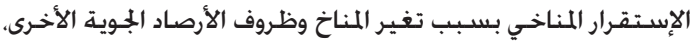

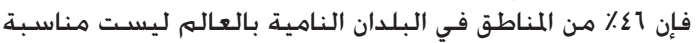

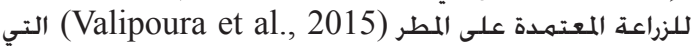

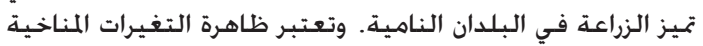

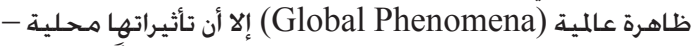
أى تختلف على الكرة الأرضية من مكان الى مكان نظراً لحسـاسية محسية
المشكلة البحثية

تعد ظاهرة التغيرات المناخية من أحد أكبر المشكلات البيئية التي

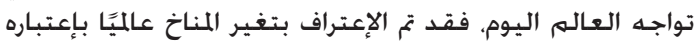

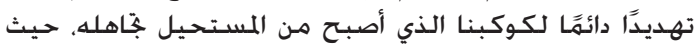

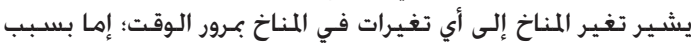

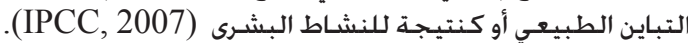

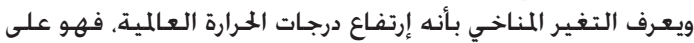

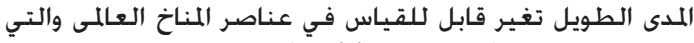

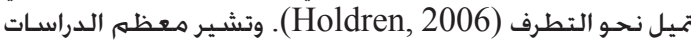

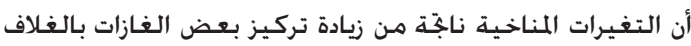

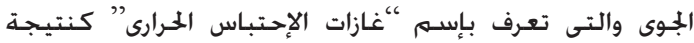

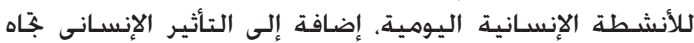

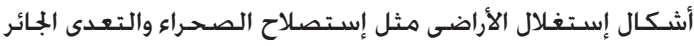

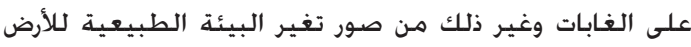

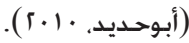

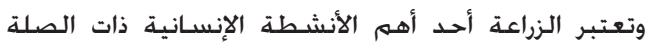
بالنظم الطبيعية والمناخية، حيث الأنشطة الزراعية حساسة الأسة ذانة 


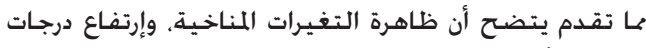

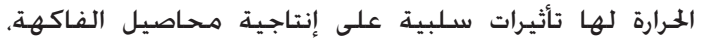

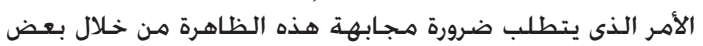

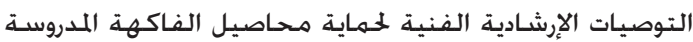

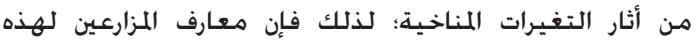

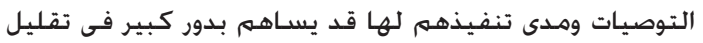

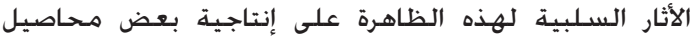

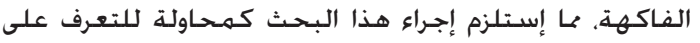

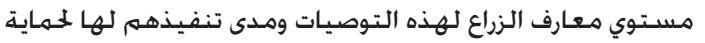

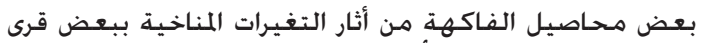

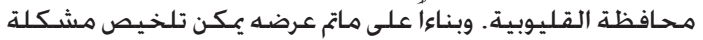
البحث في محاولة الإجابة على التساؤلات التالية:

1) ماهى معارف الزراع المبحوثين للتوصيات الإرشادية الخاصة

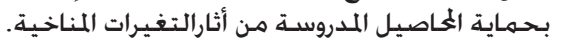

r) مامدى تنفيذ الزراع المبحـوثين لهذه التوصيات الإرشادية الخاصة بحماية هذه المحاصيل من أثار التغيرات المناخية.

أهداف البحث

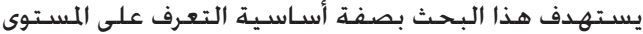

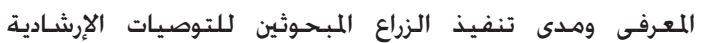

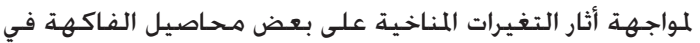

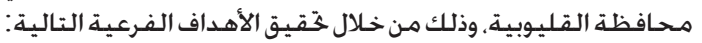

ا - التعرف علي مستوى معارف الزراع المبحـوثين للتوصيات الإرشـادية

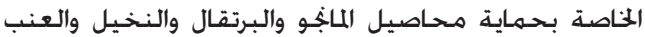
والزيتون من أثارالتغيرات المناخية في محافظة ولئة القليوبية.

ז- التعرف علي مستـوى تنفيذ الزراع المبحوثين للتوصيات الفنية

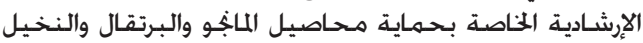

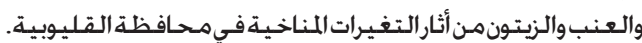
r- تحديد العلاقات الإرتباطية والإنحـدارية بين المتغيرات

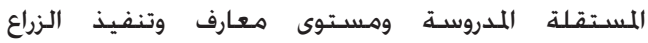
المبحوثين للتوصيات الإرشادية الخاصة بلماتية بحماية محاصيل

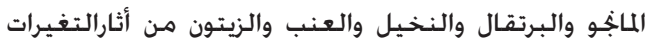
المناخية في محافظة القليوبية.

الطريقة البحثية

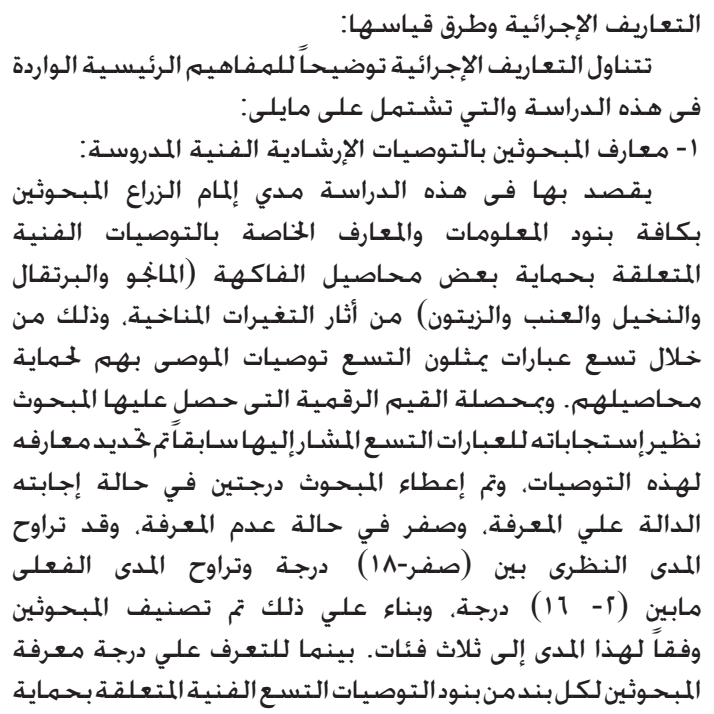

وطبيعة النظم البيئية في كل منطقة - ولذا فإنه من الأهمية

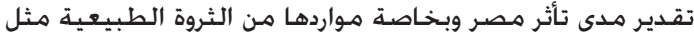

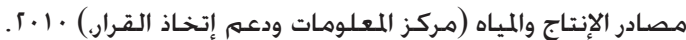

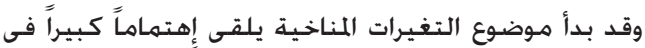

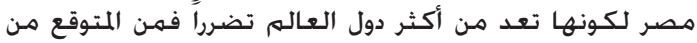

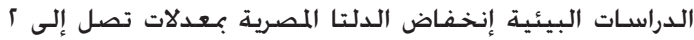

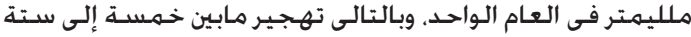

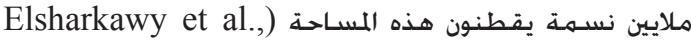

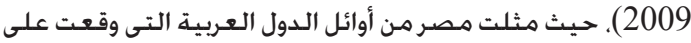
إتفاقية (UNFCCC) الأم المتحدة الإطارية للتغيرات المناخية المنية

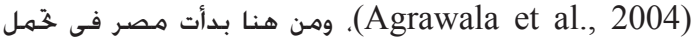

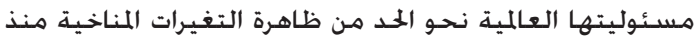
فترة طويلة خاصة من الناحية البحثية.

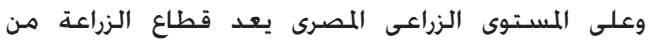

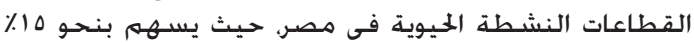

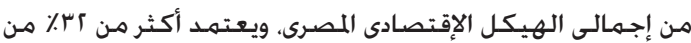

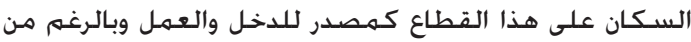

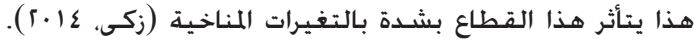

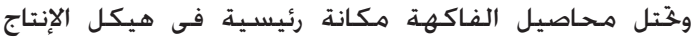

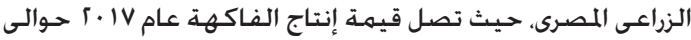

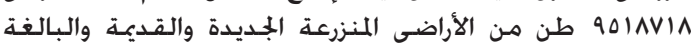
اOSIVA

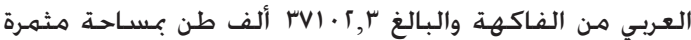

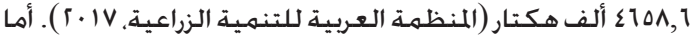

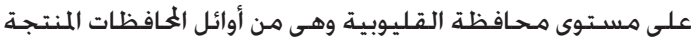

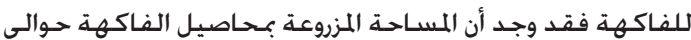
TAVID

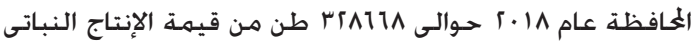

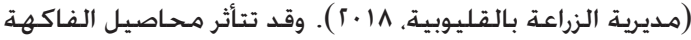

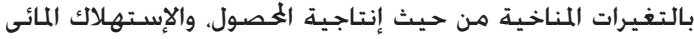

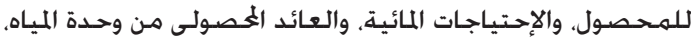

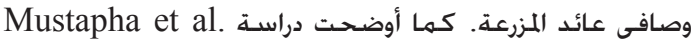

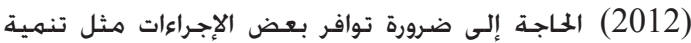
رأس المال البشـرى، وتوفير قروض صغيرة البرة للريفيين، وتقديم خدمات الاجريات

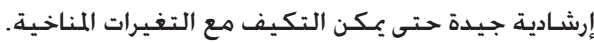

وفى هذا السياق ومع إهتمام وزارة الزراعة بتطوير أشـكال

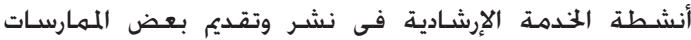

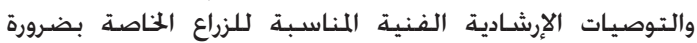

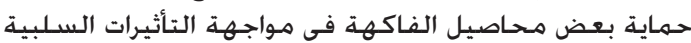

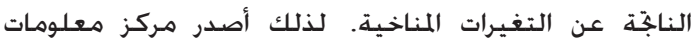

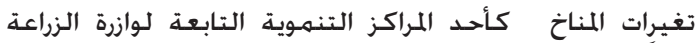

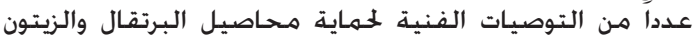

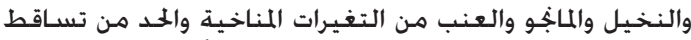

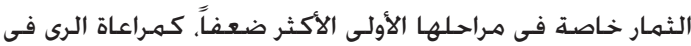

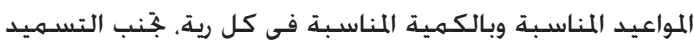

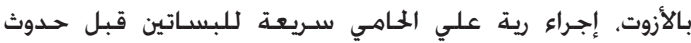

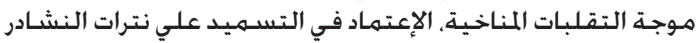

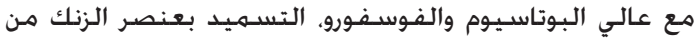

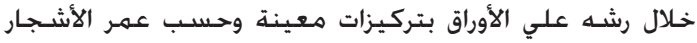

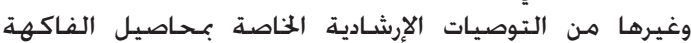

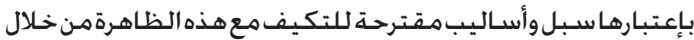

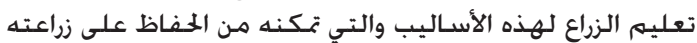

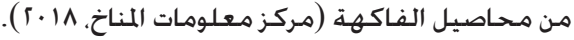

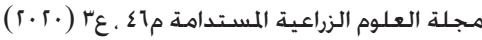


لمواجهة المشاكل الناجّة عن التغيرات المناخية، ويشار إليه

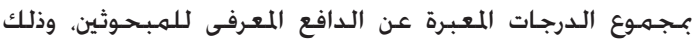

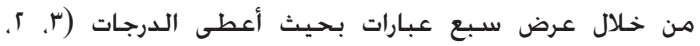

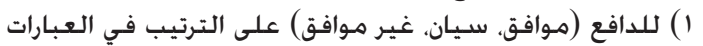

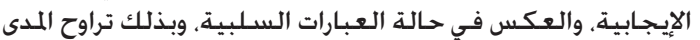

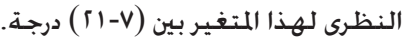

V- المشاركة في المنظمات الجُتمعية الرسمية: يقصد بها مدي معرفة المنات (مشاركة) المزارعين المبحـوثين

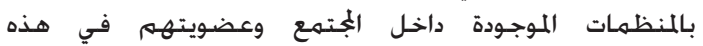

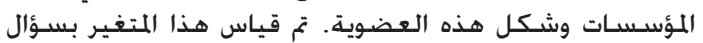

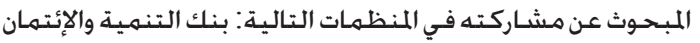
الزراعى، الجمعية التعاونية الإئتمانية الزراعية، إدارات التواتية التنمية الإنية

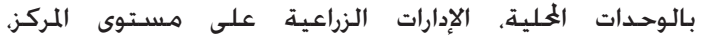

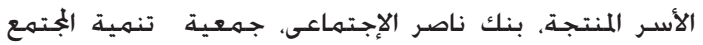

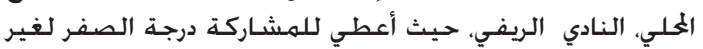

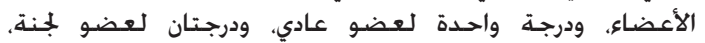

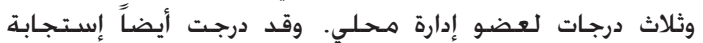

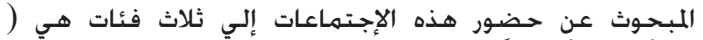

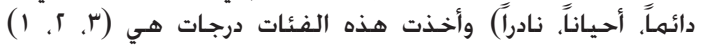

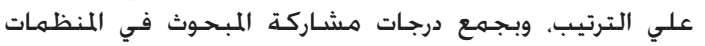

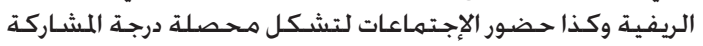

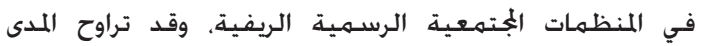
النظري لهذا المتغير بين (صفر - عـ) درجة.

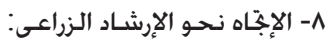

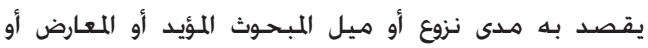

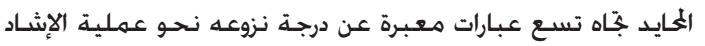

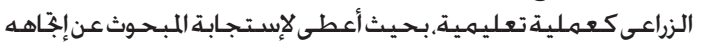

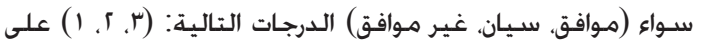

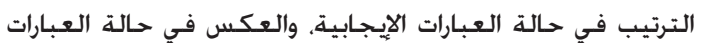

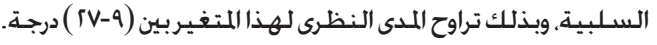

9- التعرض لبعض طرق الإتصال الإرشادية:

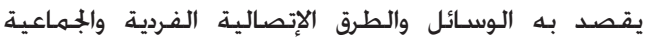

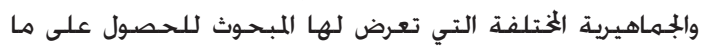

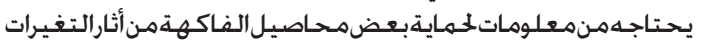

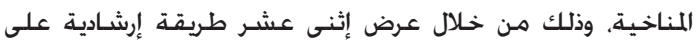

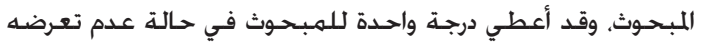

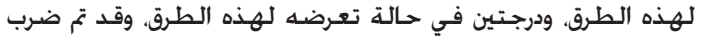

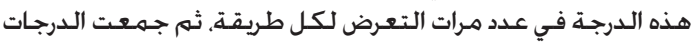

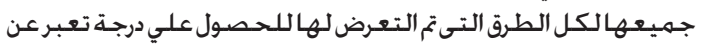
التعرض لبعض طرق الإتصال الإرشادية لدي المبحـوث.

منطقة البحث

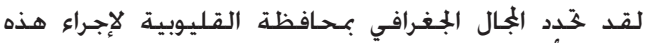

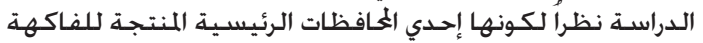

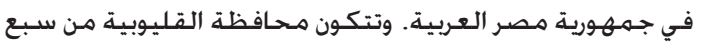

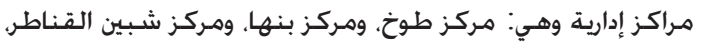

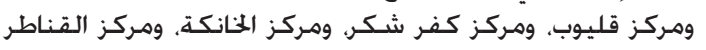

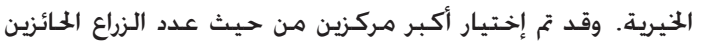

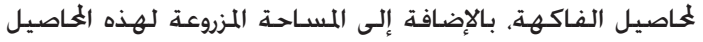

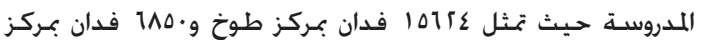

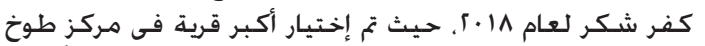

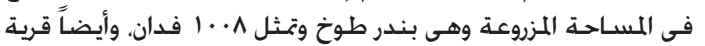

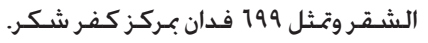

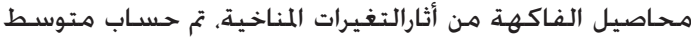

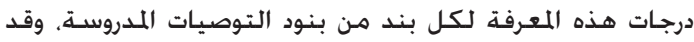

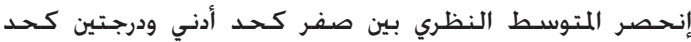

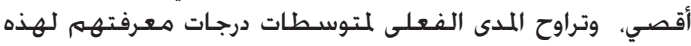

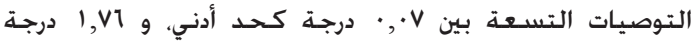

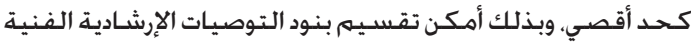

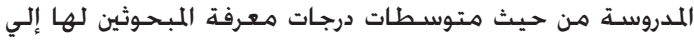

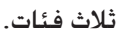

ا- - تنفيذ المبحوثين للتوصيات الإرشادية الفنية المدروسـة:

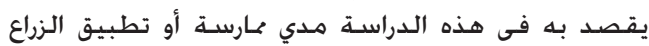

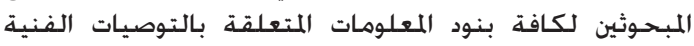

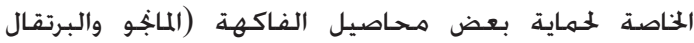

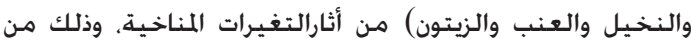

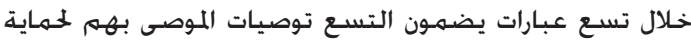

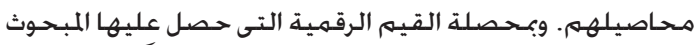

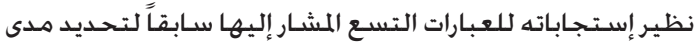

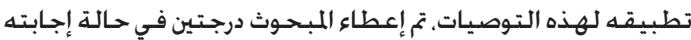

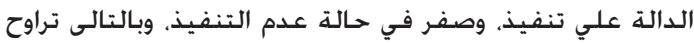

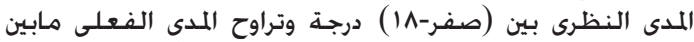

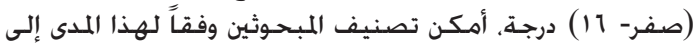

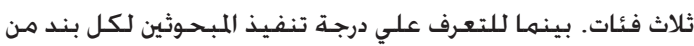

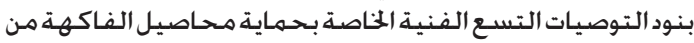

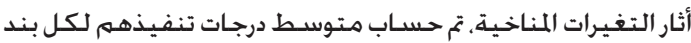

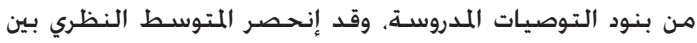

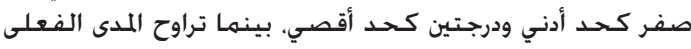

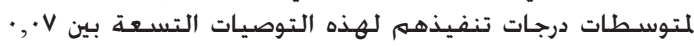

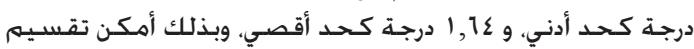

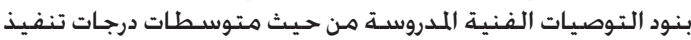
المبحوثين لها إلي ثلاث فئات.

ب- بالمالة التعليمية للمبحوث:

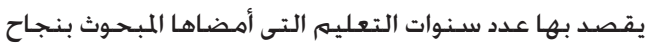

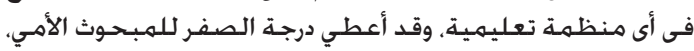

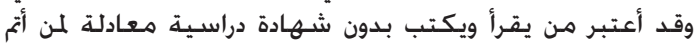

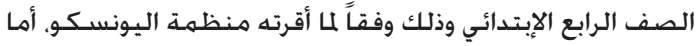

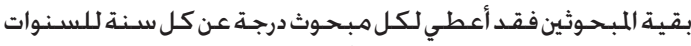

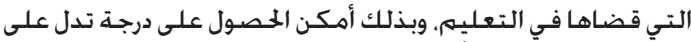

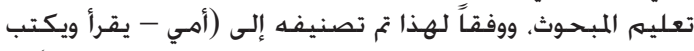

بدون شهادة- تعليه متوسط - تعليم فوق متوسط المي ومرتفع).

$$
\text { ع- الحيازة الأرضية المزرعية : بلمهان }
$$

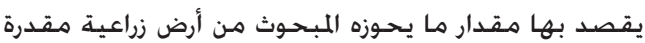
بالقيراط سـواء كانت ملكاً أم إيجار أو بالمشـاركة.

ه- درجـة الإسـتعداد للتـجديد: يقصد بها درجة أو قدرة المبحوث على على قبول الماد الأفكار

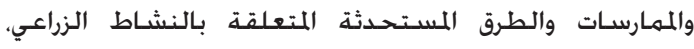

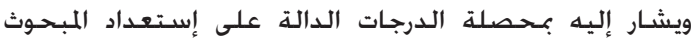

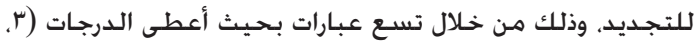

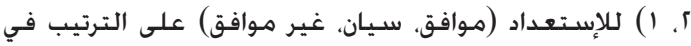

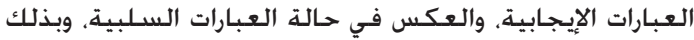

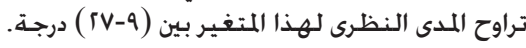

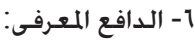

يقصد بـه قدرة المبحـوث على التفكير والبحث لمعرفة الحلول

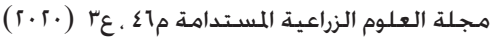


وقد إشــمل الإستبيان على قسـمين رئيسـيين: القســم الأول:

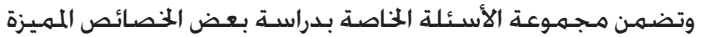

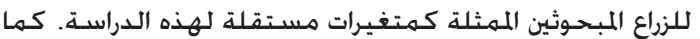

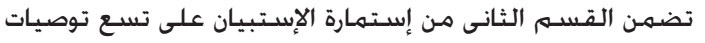

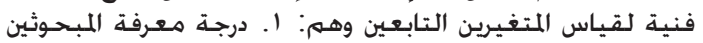

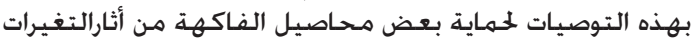

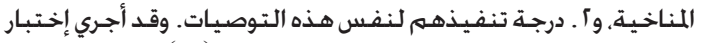

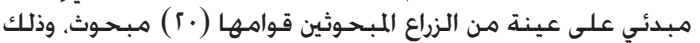

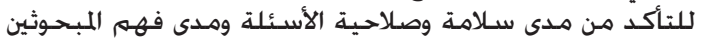

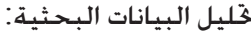

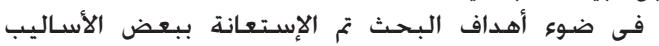

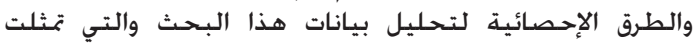

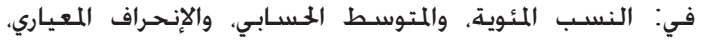

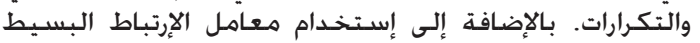

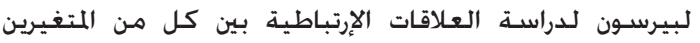

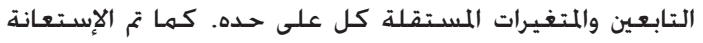

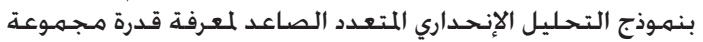

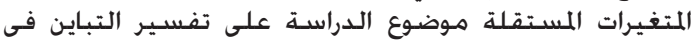

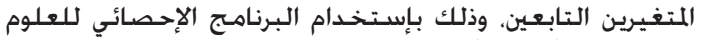

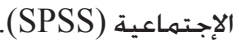

النتائج و المناقشة النماعة

أولاً : الخصائص المميزة للمبحوثين

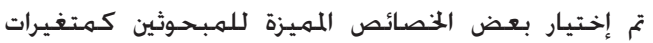

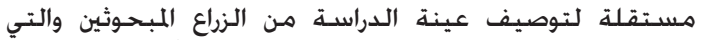

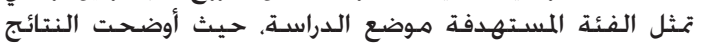

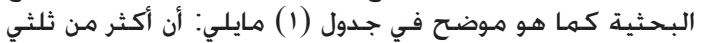

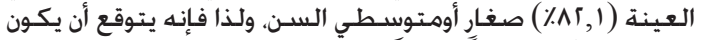

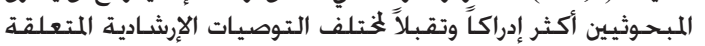

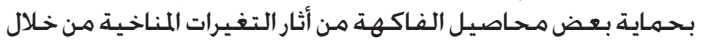

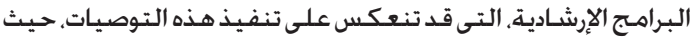

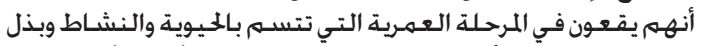

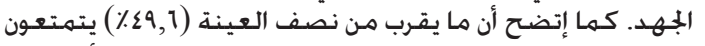

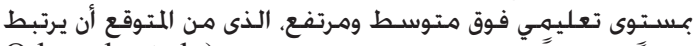

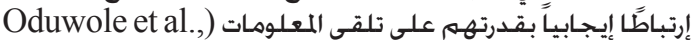

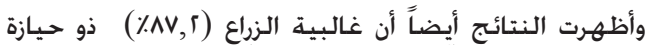

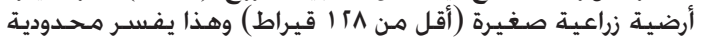

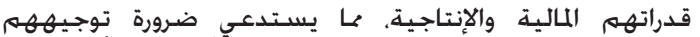

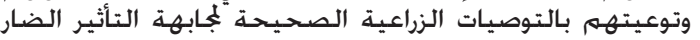

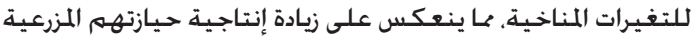

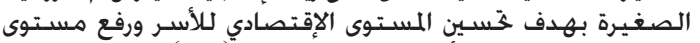

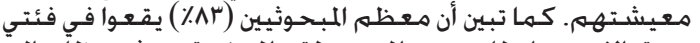

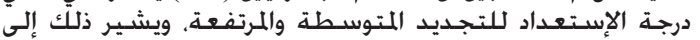

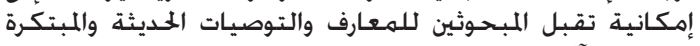

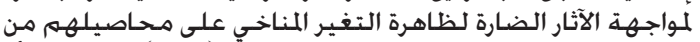

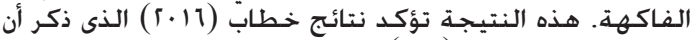

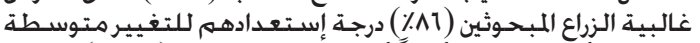

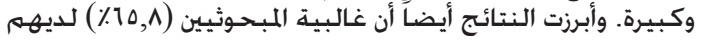

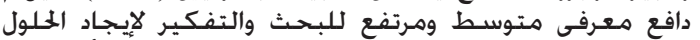

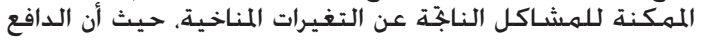

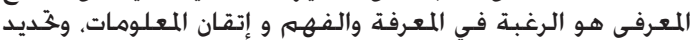

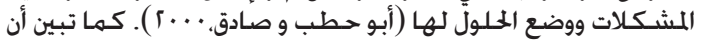

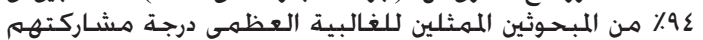

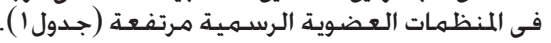

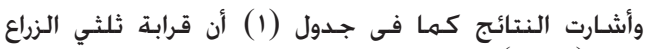

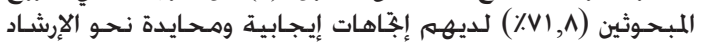

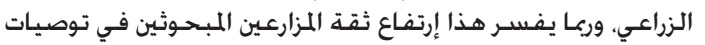

الشاملة والعينة للبحث

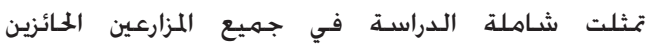

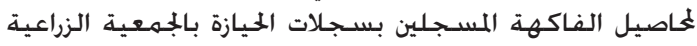

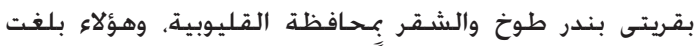

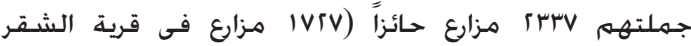

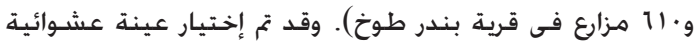

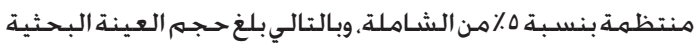

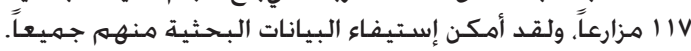

المتغيرات البحثية

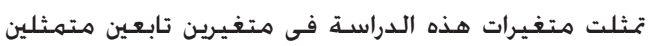

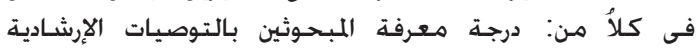

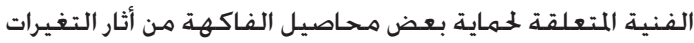

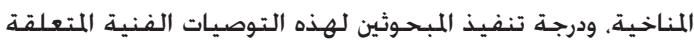

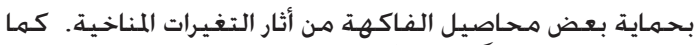

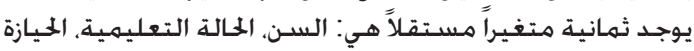

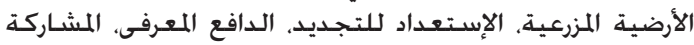

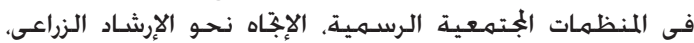
التعرض لطرق الإتصال الإرشادية.

الفروض البحثية

لتحقيق الهدف الثالث من البحـث، تم صياغة هذين الفرضين:

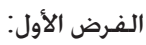

توجد علاقة إرتباطية بين المتغيرات المستقلة المدروسـة الماتهة

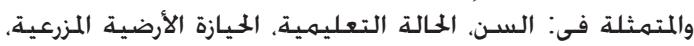

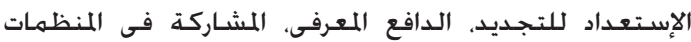

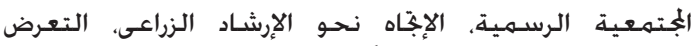

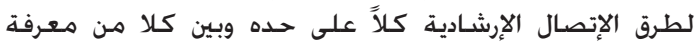

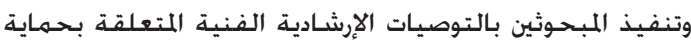
بعض محاصيل الفاكهة من أثار التغيرات المناخية.

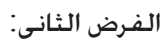

يساً فيهم كل متغير من المتغيرات المستقله المدروسـة إسـهاما

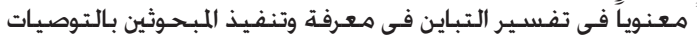

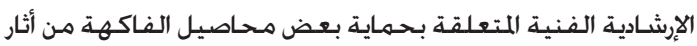
التغيراتالمناخية.

وللتأكد من صحـة هذة الفروض تم إختبار الفروض فى

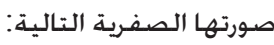

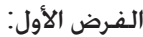

لا توجد علاقة إرتباطية بين المتغيرات المستقلة المدروسـة

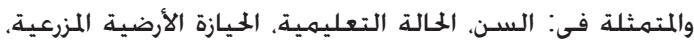

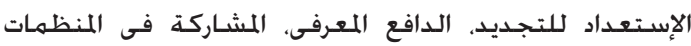

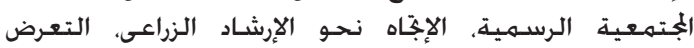

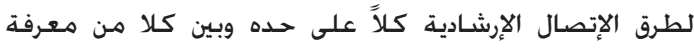

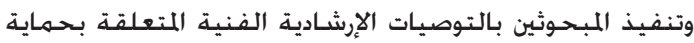
بعض محاصيل الفاكهة من أثار التغيرات المناخية.

الفرض الثانى:

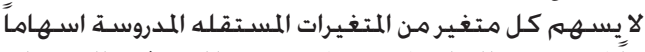

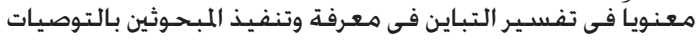

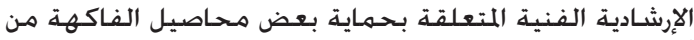
أثار التغيرات المناخية. جَميع البيانات

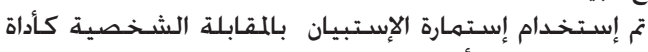

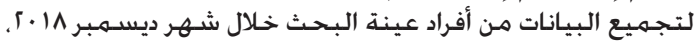

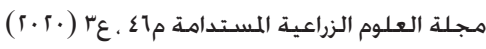




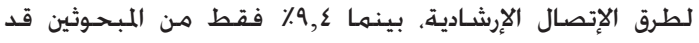

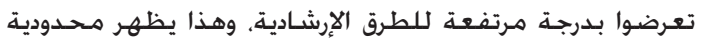

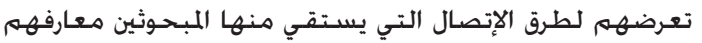

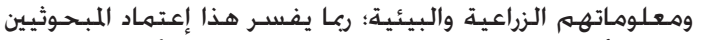

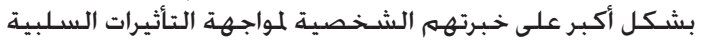

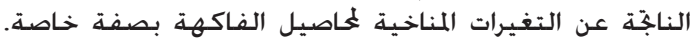

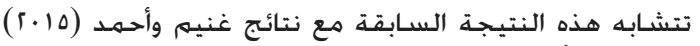

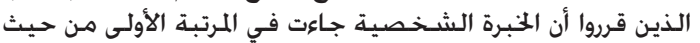

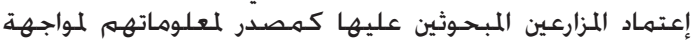

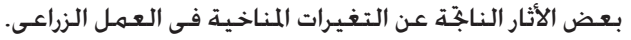

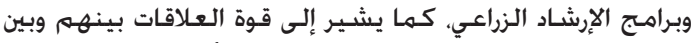

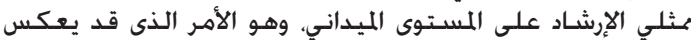

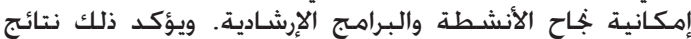

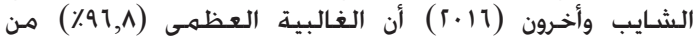

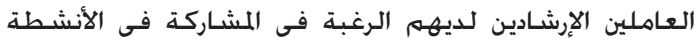

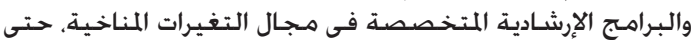

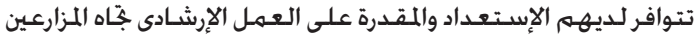

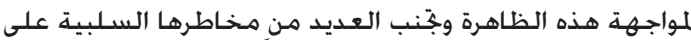

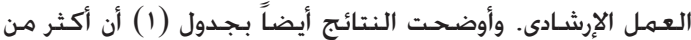

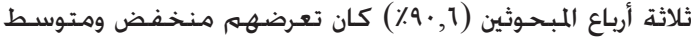

جدول ا. توزيع المبحوثيين وفقا للمتغيرات المستقلة المدروسة ( ن = I V ).

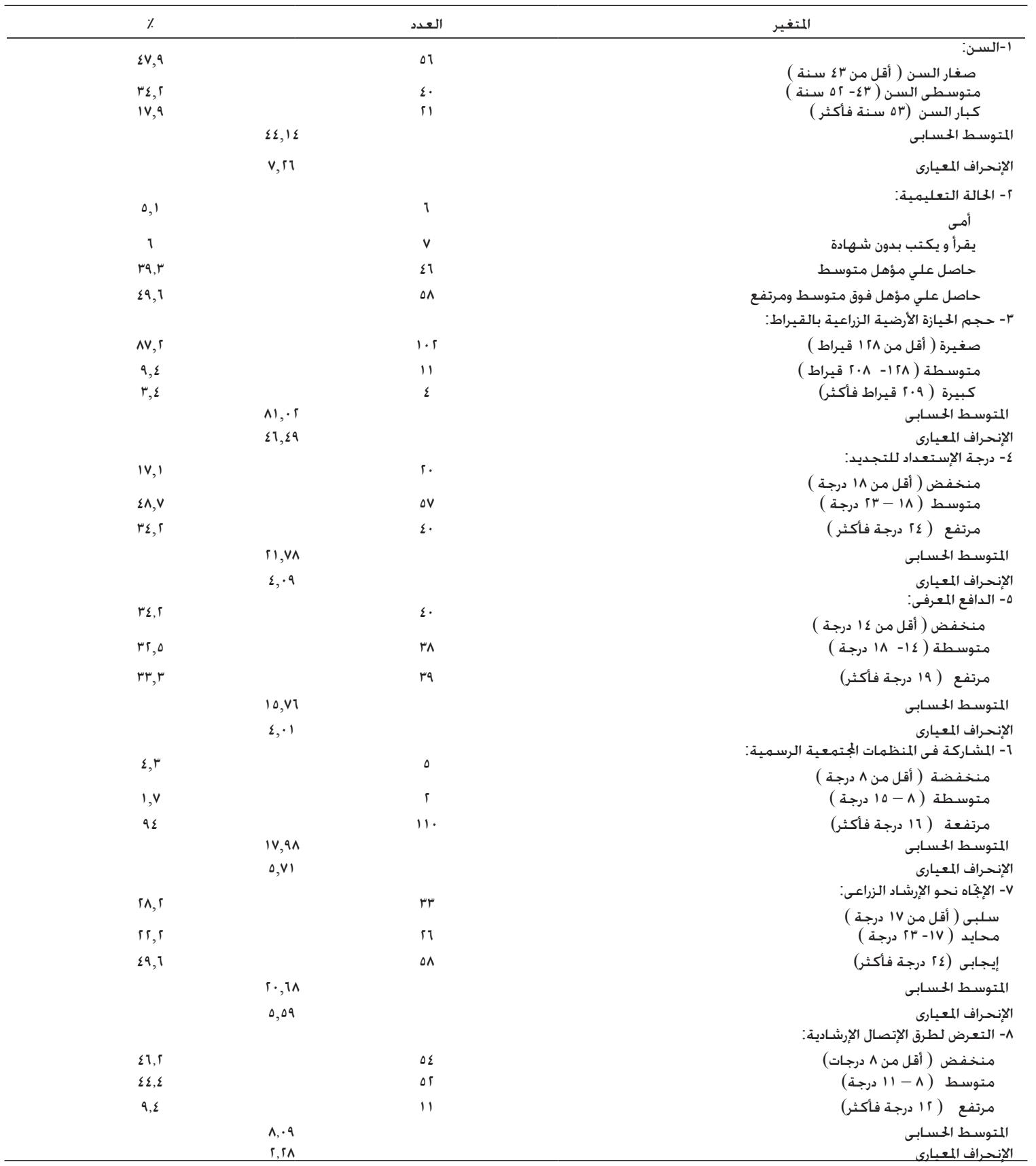




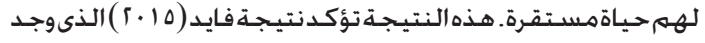
أن غالبية المزارعين المبحـوثين ( التغيرات المناخية على الزراعة كان منخفين المخاً ومتوسطياً.

وللتعرف علي درجة معرفة المبحهوثين لكل بند من من بنود

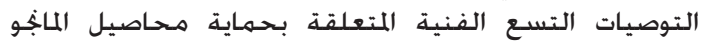

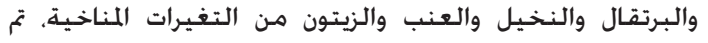

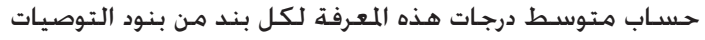

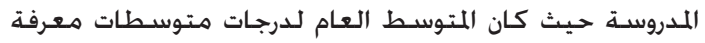

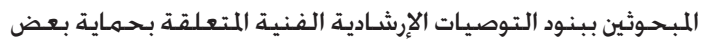

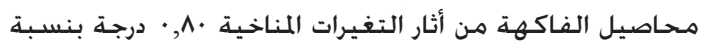

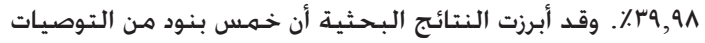

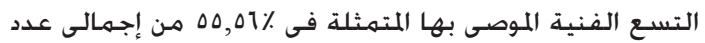

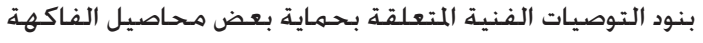

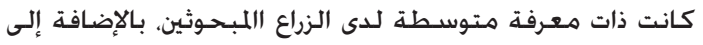

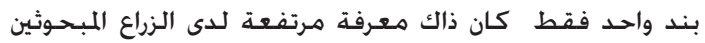

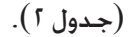

ثانياً: معارف الزراع المبحـوثين

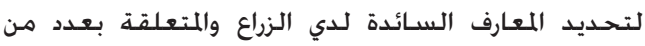

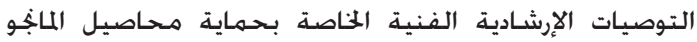
والبرتقال والنخيل والعنب والزيتون من أثار التغيرات التخاية المناخية.

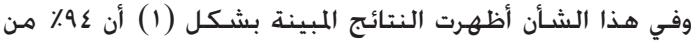

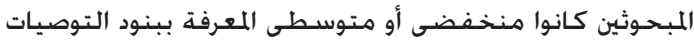

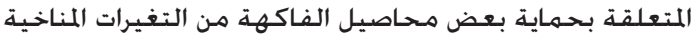

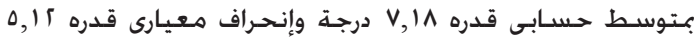

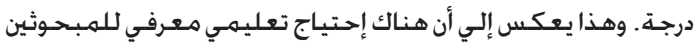

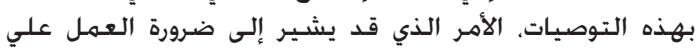

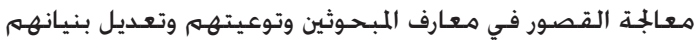

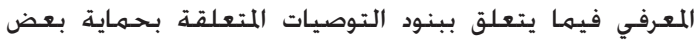

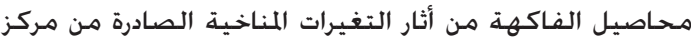

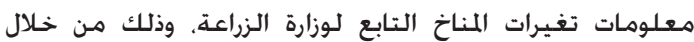

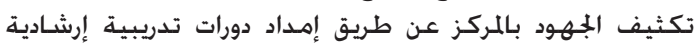

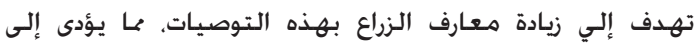

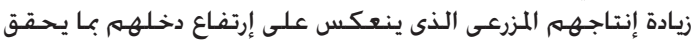

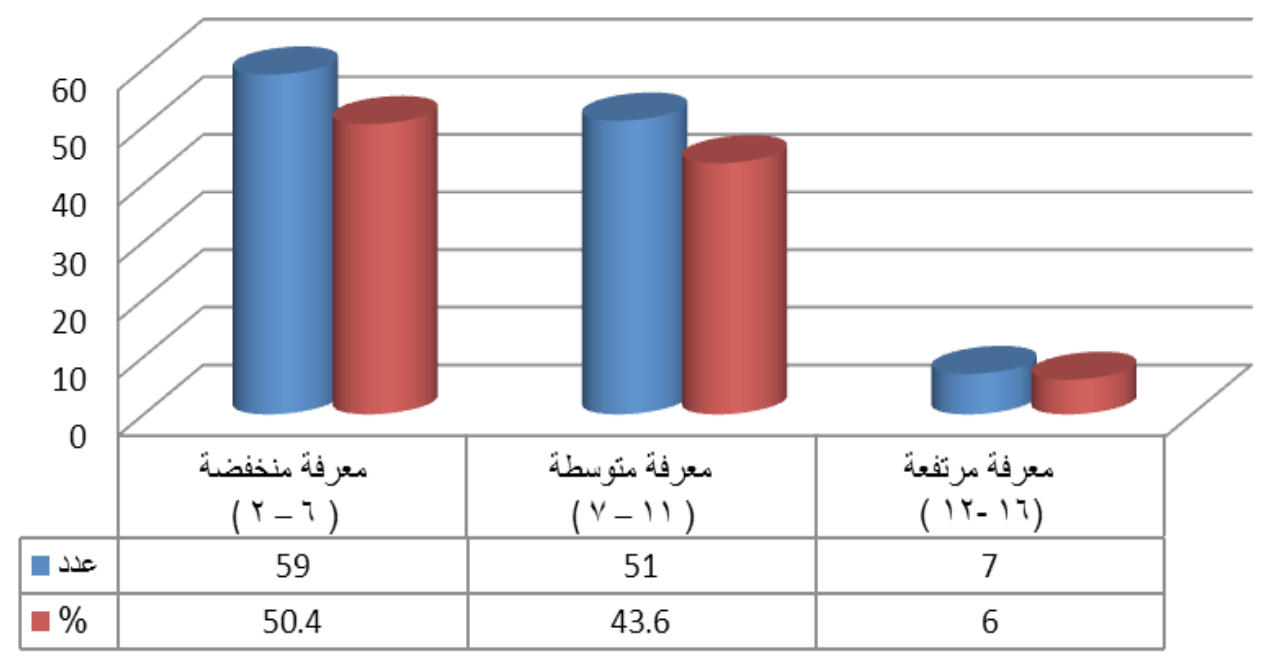

شكل ا ـ توزيع المبحوثين وفقا لفئات معرفتهم بالتوصيات الإرشادية المتعلقة بحماية بعض محاصيل الفاكهة من أثار التغيرات المناخية (ن = l V )

المصدر: جمعت وحسبت من بيانات الدراسـة الميدانية

جدول r. التوزيع العددي لمتوسطات معرفة المبحوثين لبنود التوصيات المتعلقة بحماية بعض محاصيل الفاكهة من أثثار التغيرات المناخية

\begin{tabular}{|c|c|c|}
\hline$\%$ & عدد بنود المعلومات & فئات متوسطات معرفة المبحوثين \\
\hline 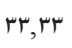 & $r$ & بنود المعرفة بها منخفضضة (أقل من سآ, · درجـة) \\
\hline$\Delta 0, \Delta 1$ & 0 & 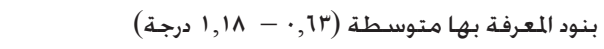 \\
\hline 11,11 & 1 & بنود المعرفة بها مرتفعة (19, 19 درجة فأكثر) \\
\hline
\end{tabular}


المانجو والبرتقال والنخيل والعنب والزيتون من التغيرات المناخية.

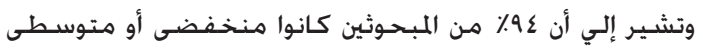

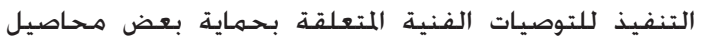

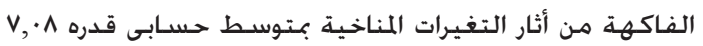

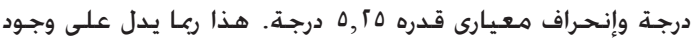

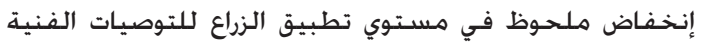

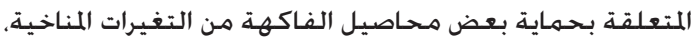

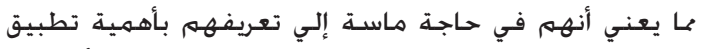

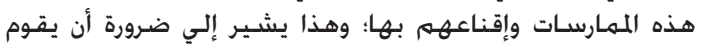

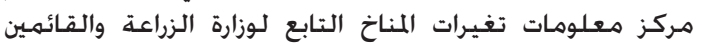

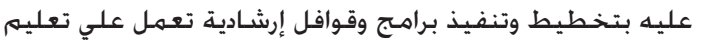

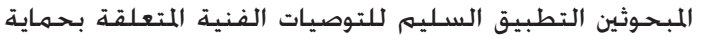

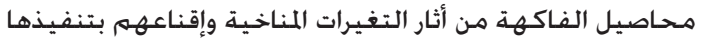

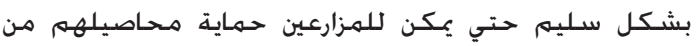

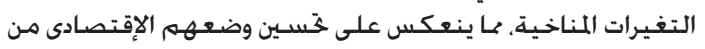

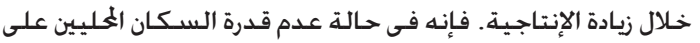

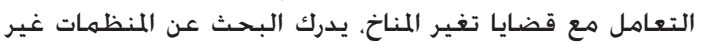

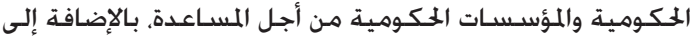

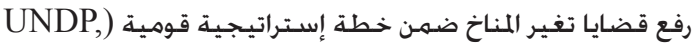

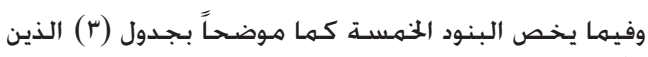

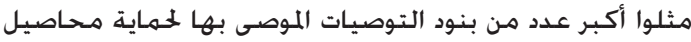

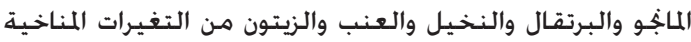

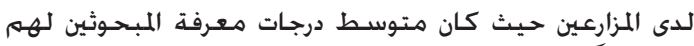

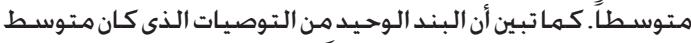

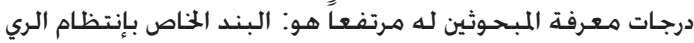

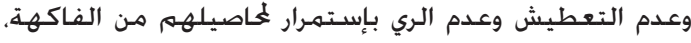

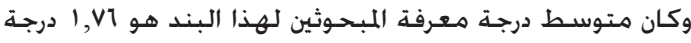

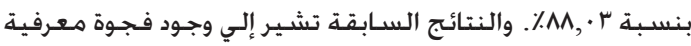

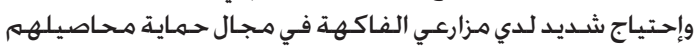

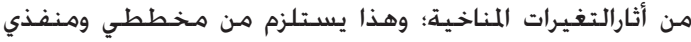

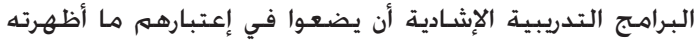

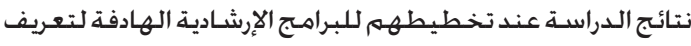

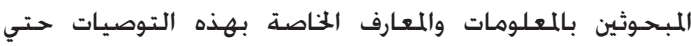

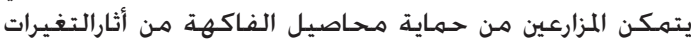
المناخية بمنطقة الدراسـة وزيادة إنتاجيتهـهم. ثالثاً: المستوى التنفيذى للزراع المبحوثين

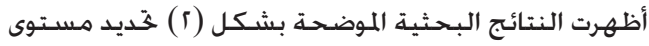

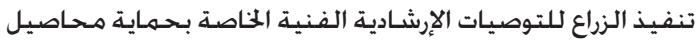

جدول ب. المتوسطاتو النسب المئوية للارجات معرفة المبحوثين ببنود التوصيات الإرشادية الفنية المتعلقةبحماية بعض محاصيل الفاكهة من أثثار التغيرات المناخية

\begin{tabular}{|c|c|c|c|c|}
\hline 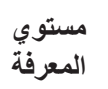 & $\%$ & متوسط درجات المعرفة & التوصيات الإرشادية الفنية المتعلقة بحماية بعض محاصيل الفاكهة من التغيرات & 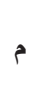 \\
\hline متوسـط & $\Delta \Gamma, 99$ & $1, \cdot 1$ & إجراء رية علي الحامي سـريعة للبسـاتين قبل حدوث موجة التغيرات المناخية. & 1 \\
\hline 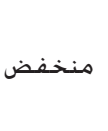 & $r, \Sigma r$ & $\cdot, \cdot \vee$ & 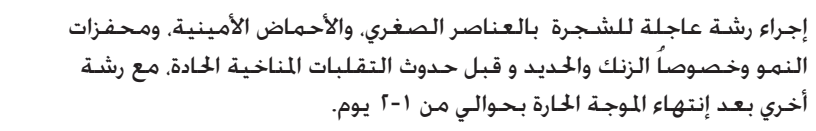 & r \\
\hline 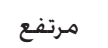 & $\wedge \wedge, \cdot r$ & $1, \mathrm{v} 7$ & إنتظام الري ومراعاة عدم الري بإســــرار وعدم التعطيش. & r \\
\hline 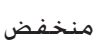 & $\varepsilon, \Gamma$ & $\cdot, \cdot 9$ & رش فوسفيت بوتاسيوم مرتين بعد • 1٪ تزهير، بحيث يكون الفاصل بينهما أسبوع. & $\varepsilon$ \\
\hline متوسط & $\Delta r, \wedge \Delta$ & $1, \cdot 1$ & 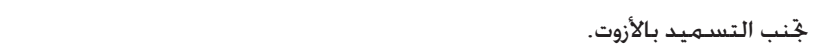 & 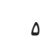 \\
\hline 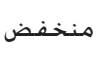 & $\varepsilon, \Gamma v$ & $\cdot, \cdot 9$ & رش كل V أيام بعد العقد، كالسيوم محمل علي أحماض أمينية مع أمينو بورون. & 1 \\
\hline متوسط & $0 \cdot, \varepsilon r$ & $1, \cdot 1$ & الإعتماد في التسـميد علي نترات النشـادر مع عالي البوتاسيوم والفوسـفورو. & $v$ \\
\hline متوسط & $0 \cdot, \varepsilon r$ & $1, \cdot 1$ & 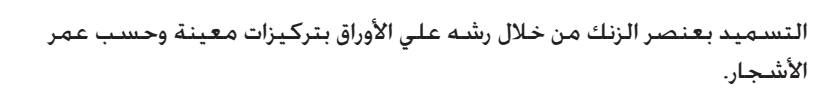 & $\wedge$ \\
\hline متوسط & $\Delta[, 1 \varepsilon$ & $1, \cdot \varepsilon$ & 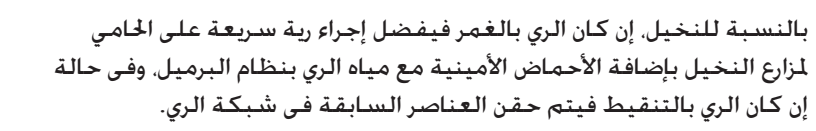 & 9 \\
\hline
\end{tabular}




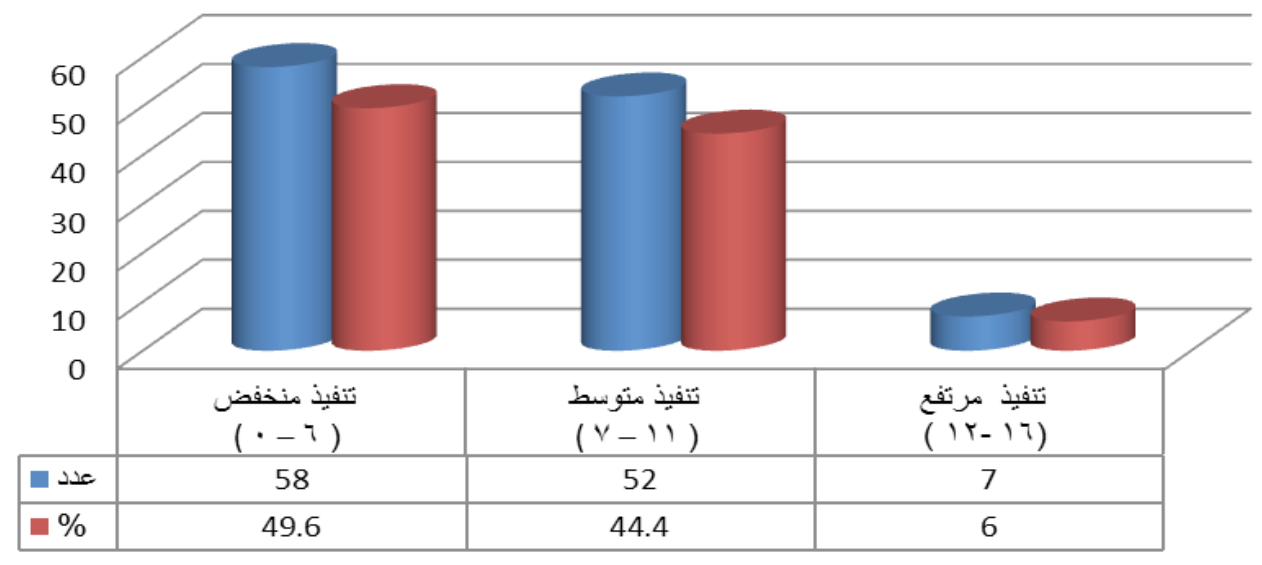

شكل r توزيع المبحوثين وفقا لفئات تنفيذهم للتوصيات الإرشادية المتعلقة بحماية بعض محاصيل الفاكهة من أثار التغيرات المناخية (ن = V V l C). المصدر: جمعت وحسبت من بيانات الدراسـة الميدانية

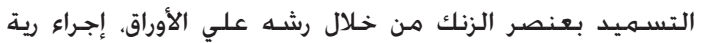

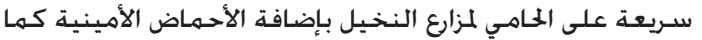

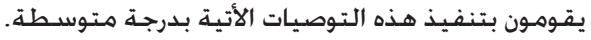

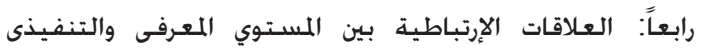

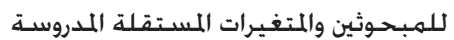

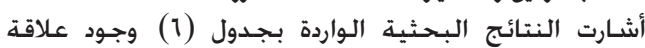

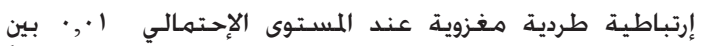

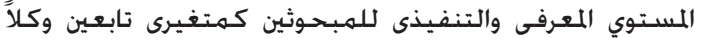

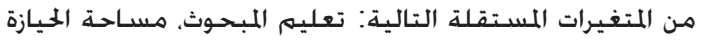

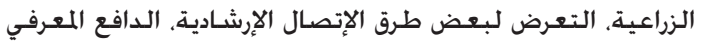

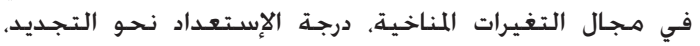

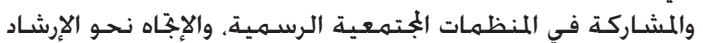

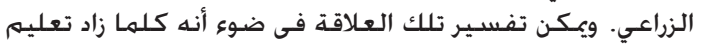

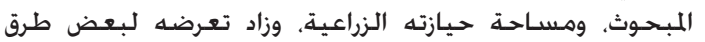

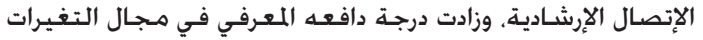

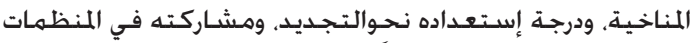

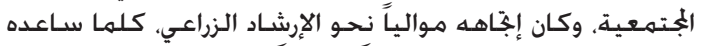

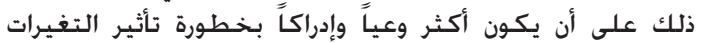

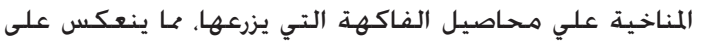

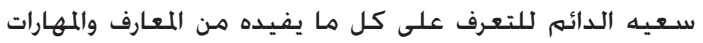

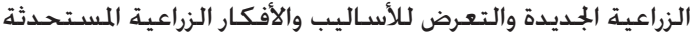

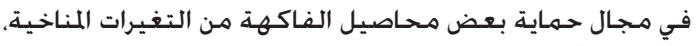

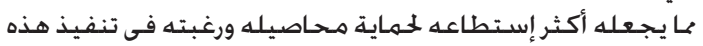

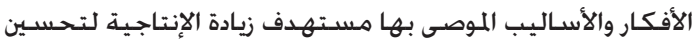

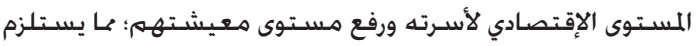

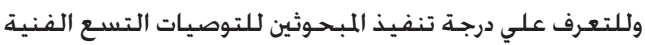

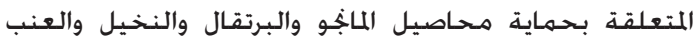

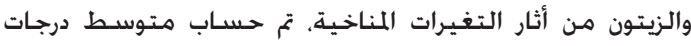

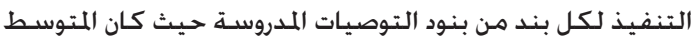

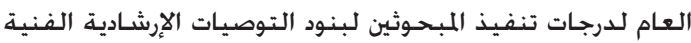

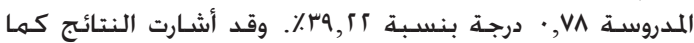

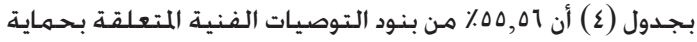

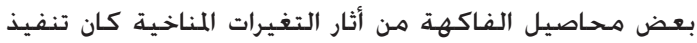

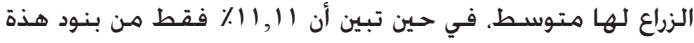

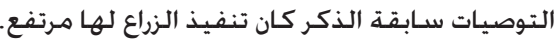

كما قد إتضح من جدول (ه) البنود الخمســة الذين مثلوا أكبر

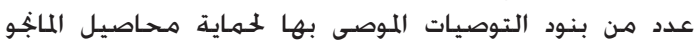

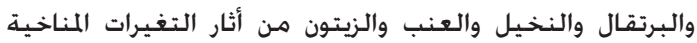

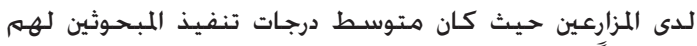

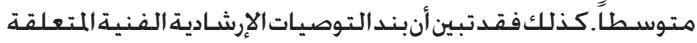

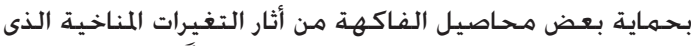

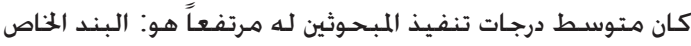

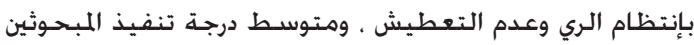

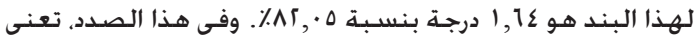

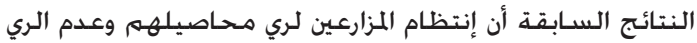

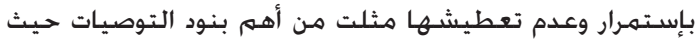

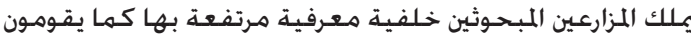

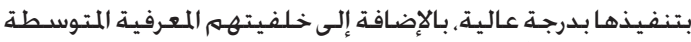

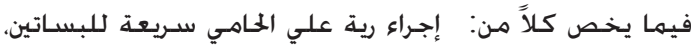

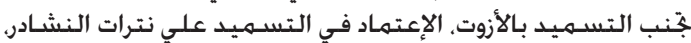

جدول ؛ ـ التوزيع العددي لمتوسطات تنفيذ المبحوثين لبنود التوصيات المتعلقة بحماية بعض محاصيل الفاكهة من أثار التغيرات المناخية

\begin{tabular}{|c|c|c|}
\hline$\%$ & عدد بنود المعلومات & فئات متوسطات تنفيذ المبحوثين \\
\hline r & $r$ & بنود تنفيذها منخفض (أقل من ه9, · درجة) \\
\hline$\Delta 0,01$ & 0 & بنود تنفيذها متوسط (ه9, · - • 1, درجـة) \\
\hline 11,11 & 1 & بنود تنفيذها مرتفع (1,11 درحة فأكثر) \\
\hline
\end{tabular}


جدول • المتوسطات والنسب المئويةلارجات تثفيذ المبحوثين لبنود التوصيات الإرشادية الفنية المتعلقةبحمايةبعض محاصيل الفاكهة من أثثار التغيرات المناخية

\begin{tabular}{|c|c|c|c|c|}
\hline مسـتوي التنفيذ & $\%$ & متوسـط درجـات التنفيذ & التوصيات الإرشـادية الفنية المتعلقة بحـماية بعض محاصيل الفـاكهة من التغيرات & a \\
\hline متوسـط & $\Delta \Gamma, 1 \varepsilon$ & $1, \cdot \varepsilon$ & إجـراء رية علي الحامي سـريعة للبسـاتين قبل حـدوث موجـة التغيرات المناخية. & 1 \\
\hline منخفض & $r, \Sigma \Gamma$ & $\cdot, \cdot \vee$ & 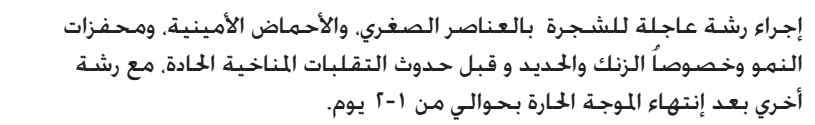 & r \\
\hline مرتفع & $\Lambda r, \Delta$ & $1,1 \varepsilon$ & إنتظام الري ومراعاة عدم الري بإستـــرار وعدم التعطيش. . & $r$ \\
\hline 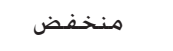 & $\varepsilon, \Gamma v$ & $\cdot, \cdot 9$ & رش فوسـفيت بوتاسيوم مرتين بعد · 1٪ تزهير، بحيث يكون الفاصل بينهـما أسبوع. & $\varepsilon$ \\
\hline متوسـط & $0 r, 99$ & $1, \cdot 1$ & جَنب التسميد بالأزوت. & $\Delta$ \\
\hline 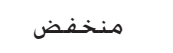 & $\varepsilon, \Gamma v$ & $\cdot, \cdot 9$ & رش كل V أيام بعـد العقد، كـالسيوم مــمل علي أحماض أمينية مع أمينو بورون. & 1 \\
\hline متوسـط & $\Delta \cdot, \Sigma \Gamma$ & $1, \cdot 1$ & الإعتـماد في التسـميد علي نترات النشـادر مع عالي البوتاسـيوم والفـوسـفورو. & $v$ \\
\hline متوسـط & $\Delta \cdot, \Sigma \mu$ & $1, \cdot 1$ & 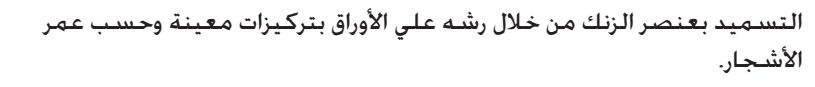 & $\wedge$ \\
\hline متوسـط & $\Delta r, 99$ & $1, \cdot 1$ & 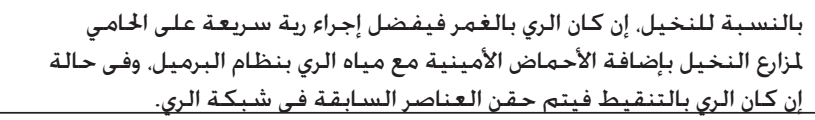 & 9 \\
\hline
\end{tabular}

المصدر: جمعت وحسبت من بيانات الدراسـة الميدانية

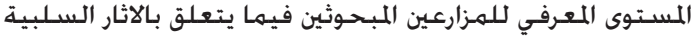

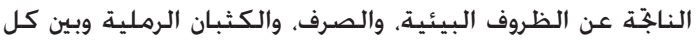

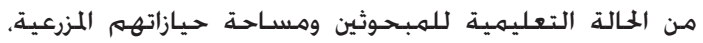

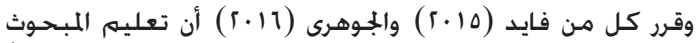

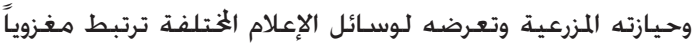

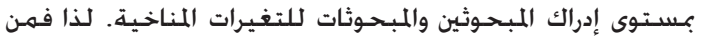

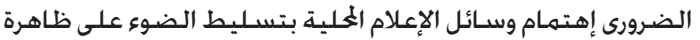

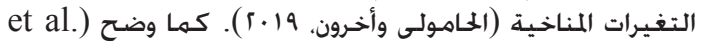
وجـود علاقة إرتباطية إيجابية بين كلاً من Chouhan (2018

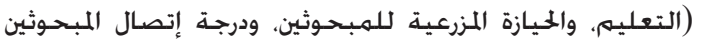

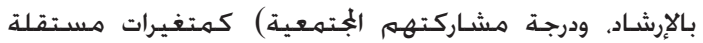

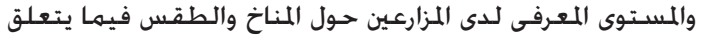
بإدارة محاصيلهـهم التزراعيـة.

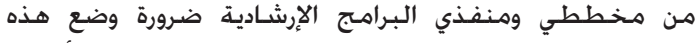

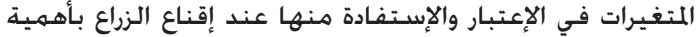

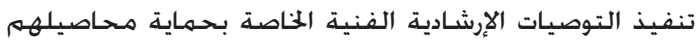

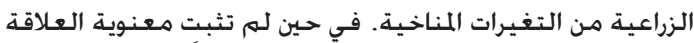

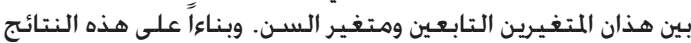

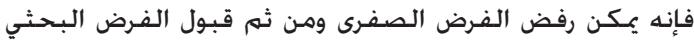

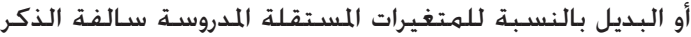

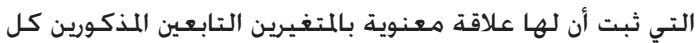

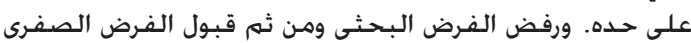

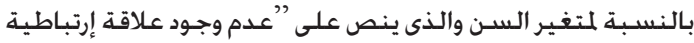

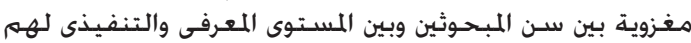

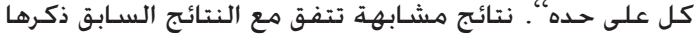

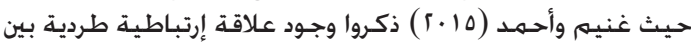

جدول ج. العلاقات الإرتباطية بين مستوي معرفة وتنفيذ المبحوثين للتوصيات الفنية لحماية بعض محاصيل الفاكهة من أثار التغيرات المناخية والمتغيرات

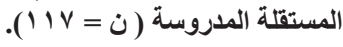

\begin{tabular}{|c|c|c|}
\hline قيم معامل الإرتباط & قيم معامل الإرتباط ومستويات & المتغيرات المستقلة المدروسة \\
\hline$\cdot, \cdot 11$ & $\cdot, \cdot 1 \wedge$ & 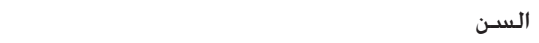 \\
\hline$* *, 1 \cdot v$ & $* *, 1 \cdot r$ & درجة تعليه المبحوث \\
\hline * ( & $* * \cdot$, r०A & مساحة الحيازة الزراعية \\
\hline **, & $* *, r$ rV & إجمالي درجة التعرض لبعض طرق الإتصال الإرشـادية \\
\hline$* * \cdot, \mathrm{V} \mu$ & $* *, \mathrm{vr \varepsilon}$ & درجـة الدافع المعرفي في مـجال التغيرات المناخية \\
\hline$* *,\{01$ & $* * \cdot, \leq \sum 9$ & درجـة الإســـــداد نـــو التجـديد \\
\hline$* * \cdot, \Delta \longleftarrow \varepsilon$ & $* *, \Delta \Gamma \wedge$ & درجـة المشاركة في المنظمات الجُتمعية الرسـمية \\
\hline **, ior & $* *, 101$ & درجـة الإجتاه نـــو الإرشـاد الزراعي \\
\hline
\end{tabular}

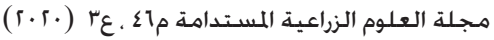


من تقلبات وتذبذب حرارى عالى وكذلك هطول الأمطارٍ يليها

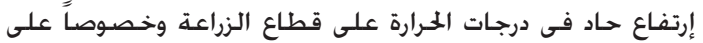

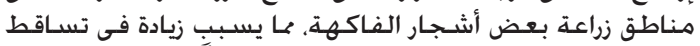

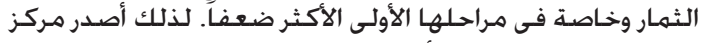

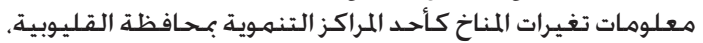

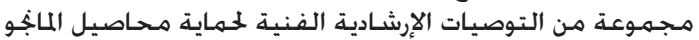

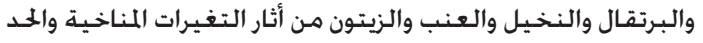

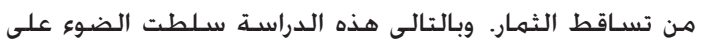

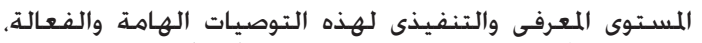

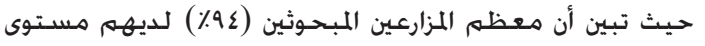

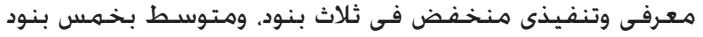

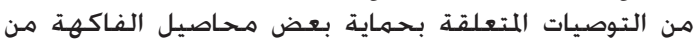

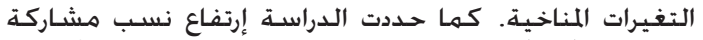

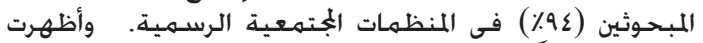

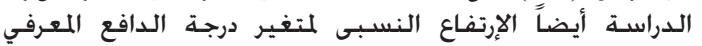

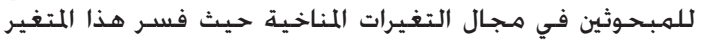

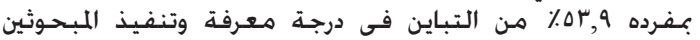

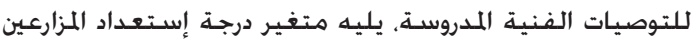

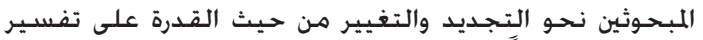

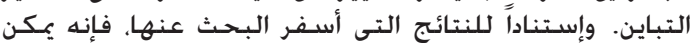
التقدم ببعض التوصيات الآتية:

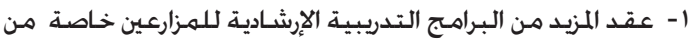

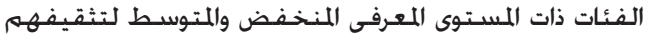

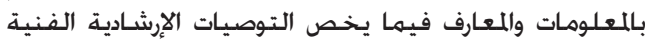

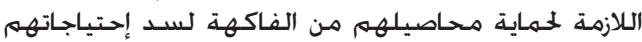
المعرفية.

؟- ضرورة التركيز على تفعيل دور المراكز التنموية في الريف مـن خلال

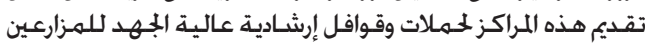

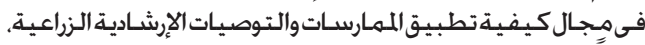

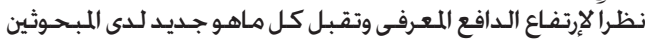

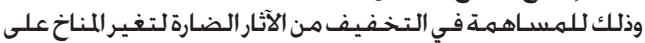
الإنتاجية الزراعية.

r- - تفعيل دور كل من المنظمات المكِّومية وغير الحكـومية عن طريق

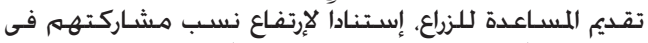

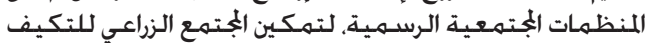

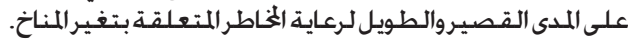

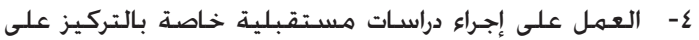

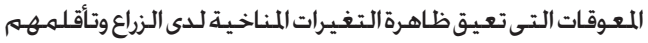

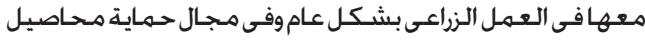

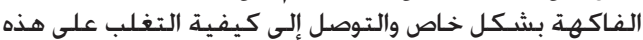

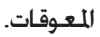

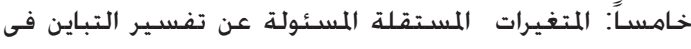

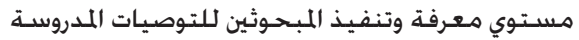

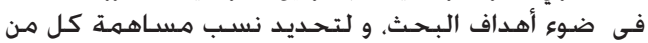

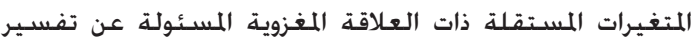

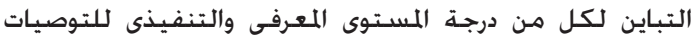

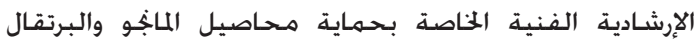

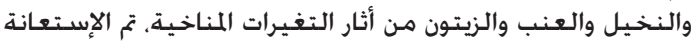

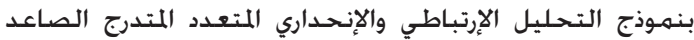

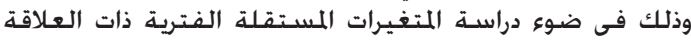

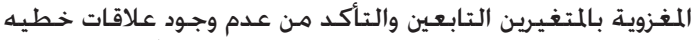

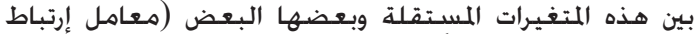

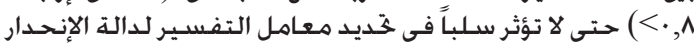

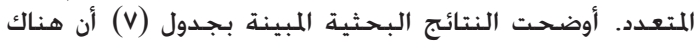

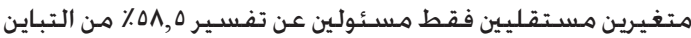

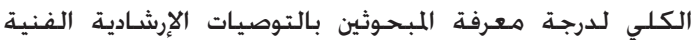

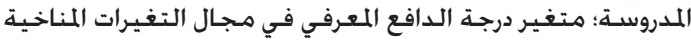

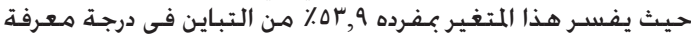

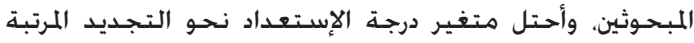

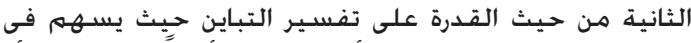

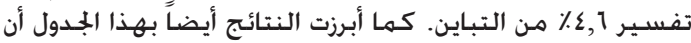

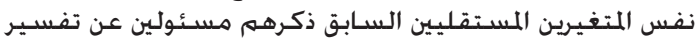

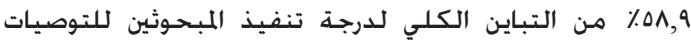

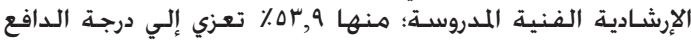

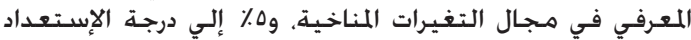

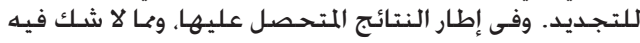

أن المزارع الذى لديه دافع معرفي مرتفع في مـال التهال التغيرات

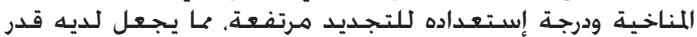

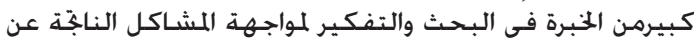

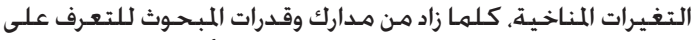

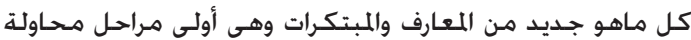

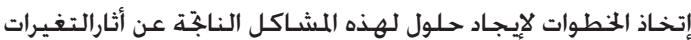

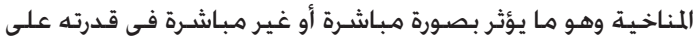

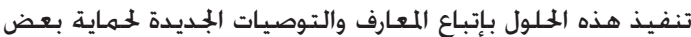

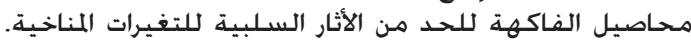

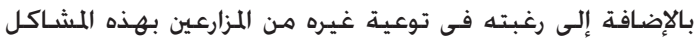

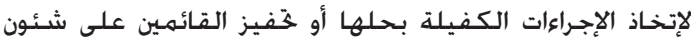

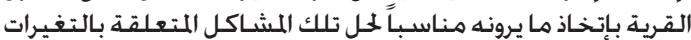

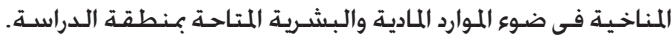

الخاتمة والتوصيات

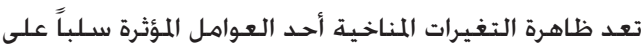

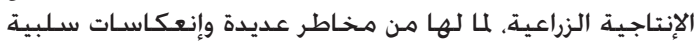

جدول V. التحليل الإرتباطي و الإنحاري المتعدد المتدرج الصاعد بين درجة معرفة وتنفيذ المبحوثين للتوصيات الفنية الخاصة بحماية بعض محاصيل الفاكهة

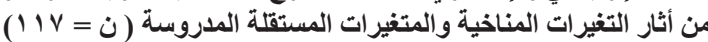

\begin{tabular}{|c|c|c|c|c|c|c|}
\hline الإنحدار معامل & للتباين المفسر المئوية & اللتباين المفسر المئوية التراكمية & الإرتباط & المتغيرات الاخلة في & \multicolumn{2}{|c|}{ خطوات التحليل } \\
\hline$* * r, \Sigma 9 \wedge$ & $\Delta r, q$ & $\Delta r, q$ & $\cdot, \mathrm{v} \varepsilon \varepsilon$ & دجرال التغيرات المناخية المعرفي في & الألخطوة & معرفة \\
\hline 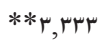 & $\varepsilon, 1$ & $\Delta \wedge, \Delta$ & $\cdot, \mathrm{v} 10$ & درجـة الإســعـداد للتجـديد & الخطوة الثانية & المبحـوثين \\
\hline$* * r, \Delta v \wedge$ & $\Delta r, q$ & $\Delta r, q$ & $\cdot, \mathrm{v} r \varepsilon$ & مجرال التغيرات المدافع المعرفي في & الأولطوة & درجـة تنفيذ \\
\hline$* * r, r q 7$ & 0 & $\Delta \wedge, 9$ & $\cdot, \mathrm{v}$ TV & درجة الإســعداد للتجديد & الخطوة الثانية & المبحوثين \\
\hline
\end{tabular}

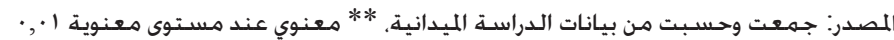


1- Agrawala, S., Moehner, A., El Raey, M., Conway, D., Van Aalst, M., Hagenstad, M. and Smith, J. (2004) Development and climate change in Egypt: focus on coastel resources and the Nile, organization for economic co-operation and development (OECD), Paris, France.

2- Chouhan, Goraknath, Suradkar, D. D. and Anarase, M. S. (2018) Farmers knowledge of climate change in relation to crop management, International Journal of Current Microbiology and Applied Sciences, Special issue. 6, 2445-2451.

3- Elsharkawy, H., Rashed, H. and Rashid, I. (2009) Climate Change: the impacts of sea level rise on Egypt. 45th ISOCARP congress. USA, on line Available at: http://www.isocarp.net/Data/case studies/1456.pdf.

4- Holdren, J.P. (2006) Meeting the climate-change challenge.retrieved, on line Available at: http:// www.whrc.org/resources/essays/2005-2006. html\&sthash.Vdkm3Kif. dpu.

5- IPCC (2007) Climate Change: the Physical Science Basis, Summary for policy makers, on line Available at: http://www.ipcc.ch.

6- Mustafa, S.B., Undiandeye, U.C. and Gwary, M.M. (2012) "The role of extension in agricultural adaptation to climate change in the sahelian zone of Nigeria", Journal of Environment and Earth Science, 2(6), 48-58.

7- Oduwole, O., Ndagi, I., Taiwo, O., Muhammed, I. and Rahman, S. (2013) Socio-economic factors affecting use of information sources among cashew farmers in Niger state, Nigeria, Journal of Agriculture and Environmental Sciences, 13(6), 769-773.

8- Osbahr, H., Twyman, C., Adger, W. N. and Thomas, D.S.G. (2008) Effective livelihood adaptation to climate change disturbances: scale dimension of practice in Mozambique. Geoforum, 39 (6), 1951- 1964.

9- UNDP (2012) Promoting climate resilient water management and agricultural practices (NAPA Follow-Up), report on: awareness and knowledge level on climate change and adaptation practices, Save Cambodia's Wildlife (SCW), Cambodia, June 2012

10- UNFCCC (United Nations Framework Convention Climate Change) (2007) Climate Change: impacts vulnerability and adaptation in developing countries, on line, Available at: http://unfecc.int/ resource/docs/publications/impacts.pdf.Retrieved on $04 / 09 / 2013$.

11- Valipoura, M., Ahmed, M.Z., Raeini-Sarjazp, M., Sefidkouhib, M. A.G., Fazlolab, A.S.R. and Darzi-Naftchalip, A. (2015) Agricultural water management in the world during past half century, Archives of Agronomy and Soil Science, 61 (5), 657-678.

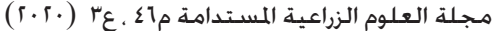

المراجع البحثية

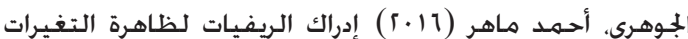

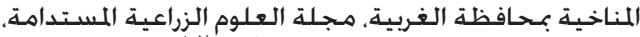

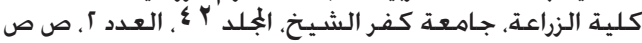

r11 - ror

الحامولى، عادل إبراهيه محسمد على، عبد الخالق على إسـماعيل.

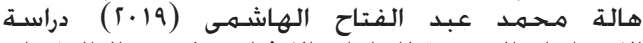

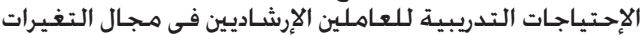

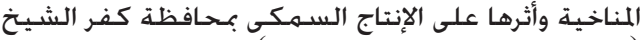

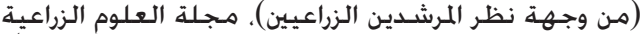

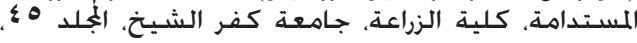

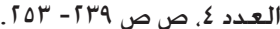

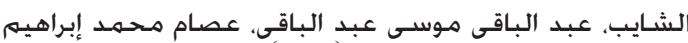

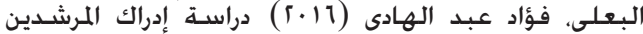

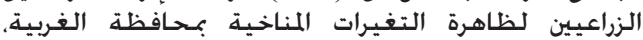

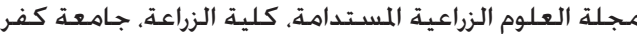

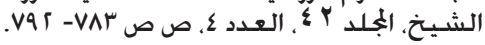

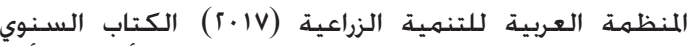

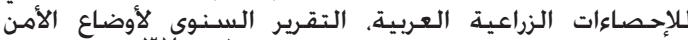

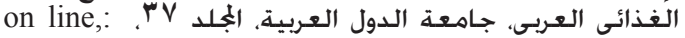
http://www.aoad.org/Arab_food_Security_Available at Report_2017.pdf

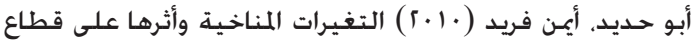

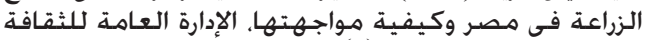

الزراعية نشـرة فنية رقهم (9).

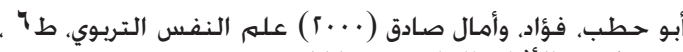

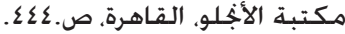

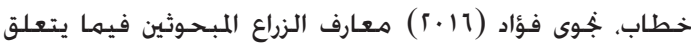

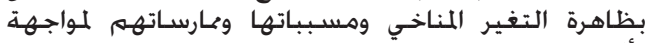

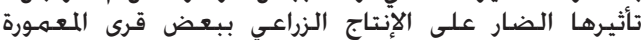

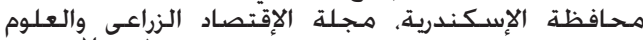

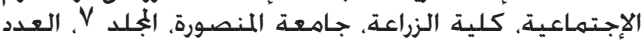

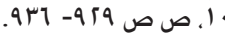

زكى، محمد عادل (2013) الجهاز المركزى المصرى للتعبئة العامة إلمانة

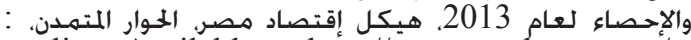
on line, Available at http://www.m.ahewar.org/s. . =asp?aid=419688\&r

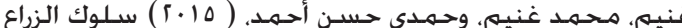

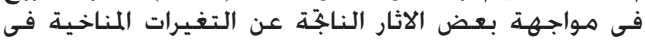

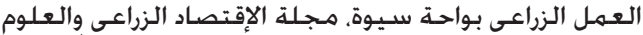

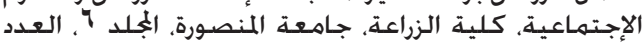

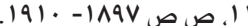

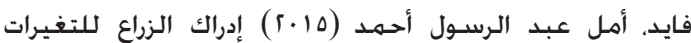

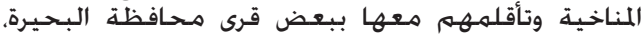

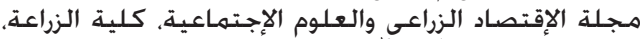

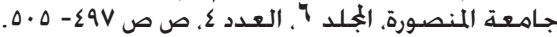

مديرية الزراعة بالقليوبية (1/.「) وزارة الزراعة وإستصلاح الأراضى، بيانات غير منشـورة، بنها، القليوبية.

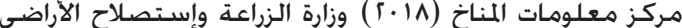

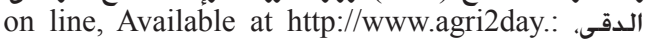
com/2018/05/06.pdf

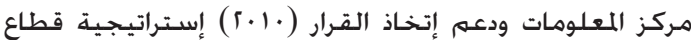

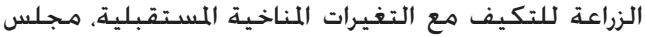
الوزراء المصري، القتاهرة. 


\title{
Farmers' Knowledge and Execution of Extension Recommendations to Mitigate Climatic Changes Effects on Some Fruit Crops in Qalyubia Governorate
}

\author{
Rabab S. A. Mohammed ${ }^{1}$ and Ola M. S. EI - Kashef ${ }^{2}$ \\ ${ }^{1}$ Department of Agricultural Economics and Extension - Faculty of Agriculture - \\ Benha University \\ ${ }^{2}$ Department of Agricultural Extension Education - Faculty of Agriculture (El-Shatby) \\ Alexandria University
}

\begin{abstract}
$\mathbf{T}$
HIS RESEARCH aims to identify the knowledge and executive level of farmers related to a number of technical extension recommendations for protecting mango, orange, palm, grape and olive crops of climatic changes in Qalyubia governorate. The two largest centers were selected in terms of the number of farmers holding fruit crops and the cultivated area of crops; the largest village in Toukh center was Bandar Toukh, and also the Al-Shaqr village in Kafr Shukr center. A questionnaire with individual interviews was carried out to collect data from a systematic random sample comprised of 117 respondent, representing $5 \%$ of the total number of fruit farmers in the selected villages, during December 2018. Data were analyzed using mean, standard deviation, percentages, and frequencies, additionally the simple correlation coefficient of Pearson, and multiple regression correlation models. Themost important results were as follows: 1) Majority of the respondents were classified as low and medium knowledge and executive level of the technical recommendation items related to protect mango, orange, palm, grape and olive crops of climate changes. 2) The results showed that there are significant positive correlation relationships between two dependent variables and education, owning a land, exposure to some extension communication methods, the knowledge motivation in the field of climate changes, the degree of readiness towards renewal, participation in formal community organizations, and attitude towards agricultural extension3 ) The results also indicated that the variable of knowledge motivation degree of respondents is responsible for the interpretation $53.9 \%$ of the variation in two dependent variables.
\end{abstract}

Keywords: Climate changes, Knowledge, Execution, Fruit crops, Technical extension recommendations, Farmers, Qalyubia Governorate. 